\title{
Patient factors associated with attrition from a self- management education programme
}

\author{
Enza Gucciardi PhD, ${ }^{1}$ Margaret DeMelo BSc RD CDE, ${ }^{2}$ Ana Offenheim BSc RN CDE, ${ }^{3}$ Sherry L. Grace PhD \\ and Donna E. Stewart MD FRCPC ${ }^{5}$
}

\author{
Keywords \\ attrition, disease self-management education, \\ patient dropout, programme evaluation, \\ retention, type 2 diabetes mellitus \\ Correspondence \\ Enza Gucciardi \\ University Health Network \\ Toronto General Hospital \\ 200 Elizabeth Street \\ Eaton Wing North، 7th Floor, Room 238 \\ Toronto, Ontario M5G 2C4 \\ Canada \\ E-mail: enza.gucciardi@uhnres.utoronto.ca
}

\begin{abstract}
Objective To examine utilization patterns of diabetes self-management training (DSME) and identify patient factors associated with attrition from these services at an ambulatory diabetes education centre (DEC).

Methods A retrospective medical chart review of first time visits (536) to the centre between 1 August 2000 and 31 July 2001 was conducted for patients with type 2 diabetes. Descriptive analyses were conducted to examine utilization patterns over a 1-year period. Multivariable logistic regression was used to identify patient factors associated with attrition from DSME and non-use of group education among new patients.

Results Almost 50\% of new patients withdrew prematurely from recommended DSME services over the 1 -year period, and only $24.8 \%$ attended group education. Patient variables such as being older than 65 years of age, primarily speaking English, or working full or part-time were associated with attrition from DSME and non-use of group education when compared with middle aged, non-English-speaking, and non-working patients.

Conclusions High DSME attrition rates indicate that retention needs to become a focus of programme policy, planning and evaluation to improve programme effectiveness. DSME tailored to the cultural and linguistic characteristics of the community, and convenient and accessible to working and older patients will potentially increase retention in and accessibility to these services.
\end{abstract}

\section{Introduction}

There is now unprecedented evidence regarding the benefits of aggressive glycemic control in reducing the risk for and delaying the progression of diabetes complications [1,2]. However, aggressive glycemic control requires a lifelong adherence to complex lifestyle management involving routine blood glucose monitoring, self-adjustment of medications, nutrition management and a physically active lifestyle. To increase diabetes self-management motivation and skills, study findings advocate patient education and close ongoing support from a health care team $[1,2]$. As a result, diabetes self-management training (DSME) has been recognized as a valuable resource that enables patients to actively participate in managing their own care. Clinical practice guidelines for diabetes management endorse ongoing DSME and continued support from an interdisciplinary diabetes health care team to successfully manage diabetes $[3,4]$. Furthermore, they also recommend periodic re-evaluation of educational needs and barriers to ongoing DSME.
Despite the reported efficacy of DSME [5,6], translation of these interventions into clinical practice has been challenging. For instance, these interventions, particularly education classes, have low participation $[7,8]$ and high attrition rates [9]. In fact, attrition rates range from $4 \%$ to $57 \%[10-15]$ in existing programmes. Patients who drop out prematurely from self-management programmes adhere less conscientiously to self-management activities and have worse glycemic control than those who continue with the recommended services $[11,13,15-17]$. Therefore, high attrition rates raise concerns regarding a patient's ability to effectively manage their disease and to optimize their health. Furthermore, DSME programmes will have limited success with high attrition, irrespective of programme efficacy $[18,19]$.

The association between attrition from DSME services and adverse clinical outcomes in persons with diabetes is consistent across the literature. What is less clear, however, is what influences a patient's decision to continue or discontinue the use of recommended services. Despite some efforts to identify attrition factors 
in education interventions [10-16,20-23] and missed diabetes care appointments [17,24-28], existing study results are conflicting. Contradictory findings can be attributed to variations in research populations, designs, attrition definitions, and study analyses across the studies. Given the limited number of studies and their conflicting results, the existing evidence regarding factors leading to attrition is inconclusive.

The following study examines DSME utilization patterns and attempts to identify patient factors associated with attrition from these services in new patients with type 2 diabetes attending an ambulatory diabetes education centre (DEC). Increasing the numbers of those who participate fully in organized DSME is best achieved by deeper insight into the reasons why so many people choose to abandon diabetes education initiatives.

\section{Methods}

\section{Research setting}

Diabetes education centres are outpatient centres designed to provide services that enable individuals to make lifestyle modifications aimed at maintaining health and preventing or delaying complications. The University Health Network Toronto Western Hospital DEC in Ontario serves one of the most urban and culturally diverse communities in Canada. The interdisciplinary DEC team consists of two endocrinologists, eight diabetes educators (four nurses and four dieticians) and a social worker. Professionals such as a physiotherapist, pharmacist and a psychologist are also available for patient consults. The DEC operates during the week from 8:30 AM to 4:00 PM.

Upon their first visit to the DEC, each patient receives a nursing and dietary assessment where mutually agreed upon management goals are established. Counselling is individualized according to a patient's identified needs and priorities. All patients are instructed to attend self-management training services (one-on-one counselling or education classes) and to return for an individual or group follow-up visit to provide an opportunity to identify barriers, problem-solve and monitor the progress of previously established goals. If patients fail to return for individual or group follow-up appointments, efforts are made to contact them by telephone. Frequency of further follow-up visits is based on patient needs and their ability to self-manage.

All services, including group education, are provided in six different languages (English, Portuguese, Cantonese, Italian, Spanish and Vietnamese) by bilingual staff or professional interpreters and address the culture and values represented by these language groups. These services do not incur a direct cost to patients as they are funded within the publicly financed provincial health care system.

\section{Research subjects and design}

After obtaining ethics approval from the University Health Network Research Ethics Board, we reviewed all medical records of patients whose initial visit to the DEC occurred between 1 August 2000 and 31 July 2001. Sampling lists were created for each language group in which services were provided in at the centre. Due to the high proportion of English-speaking patients, we systematically included every second patient (50\%) from an English- speaking alphabetical sampling list, which allowed for a more equitable distribution of language groups for the analyses. The sampling fraction for each of the non-English-speaking groups was a $100 \%$. Study participants were all diagnosed with type 2 diabetes by their referring doctor. Study exclusion criteria included patients with a diagnosis of gestational diabetes, impaired glucose tolerance only, or an unstable psychiatric condition as documented in patient files.

\section{Outcome variables}

For the most part, DSME is individualized for each patient based on severity and perceived need. There are no DSME guidelines or recommended number of educator visits or contact hours necessary for optimal diabetes management. Therefore, a standard method for measuring attrition, or retention, in DSME is challenging to define. This may explain why a standard method does not already exist in the literature. In collaboration with a panel of educators and managers from several DECs, we defined programme retention based on patient participation in the fundamental principles (i.e. initial assessment, education, and follow-up/ evaluation) of DSME defined by the American Diabetes Clinical Practice Guidelines [3]: The goal is to ensure patients acquire sufficient knowledge and skills to adequately carry out diabetes self-management activities. The panel came to the consensus that four patient-provider contacts is the minimum number of contacts needed to cover the basics components DSME. It was argued that patients should have an initial health assessment with a nurse and dietitian educator, formal diabetes self-management education/ training through counselling or education classes, and some form of follow-up. As a result, attrition was defined as not returning to the centre for at least four patient-provider contacts over the 1-year period. More than one patient-provider contact can be achieved in one DEC visit (e.g. both a nurse and dietitian assessment). For our analyses, study participants were classified as users ( $\geq 4$ patient-provider contacts) or non-users ( $\leq 3$ patient-provider contacts) of ongoing services since their first DEC visit. All patients were further classified as users or non-users of group education for our second outcome measure.

Our rationale for using a threshold of at least four patientprovider contacts (a dichotomous variable) rather than the frequency of contacts (a continuous variable) over a 1-year period is that patients at higher risk or greater severity of the disease are likely to require more care to reduce the incidence of complications, and therefore, frequency may not necessarily be the best method to measure adequate use of recommended services.

\section{Predictor variables}

We selected predictor variables based on a review of the literature (E. Gucciardi, unpublished), and what was available and complete in patients' medical charts prior to the analyses. Patient factors that were extracted from medical charts and examined as predictor variables in the analyses were sex, age, primary language spoken, employment status, travel distance to $\mathrm{DEC}(\mathrm{km})$, body mass index, type of medical management, and whether or not a patient selfmonitors their blood glucose, carries out any form of exercise and is a current smoker. 


\section{Analyses}

Using descriptive analyses we examined DSME utilization patterns. To assess the association between predictor variables and attrition from DSME services and non-use of group education, we used bivariate and multivariable logistic regression. The main measure of association was the odds ratio with its $95 \%$ confidence interval (CI). During multicollinearity testing, age, age of diagnosis and years living with diabetes were highly correlated. High correlation suggests that these variables are capturing similar information and to include them all in a regression model could make the prediction equation and regression estimates unstable and unreliable. Given that years living with diabetes appears to be unrelated to attrition in the literature review, age was selected for our analyses as a predictor.

Full multivariable logistic models were fitted for the two models, regardless of bivariate results [29]. Our study sample size of 536 was sufficient for both multivariate models based on a widely used rule of thumb that there should be 10 events per variable parameter in the model in order to obtain reliable estimates [30]. Because the second model was based on fewer events, not all of the predictor variables were entered into the model. Variable selection was based on the literature review prior to analyses. The amount of missing data were less than 5\% for all variables; therefore, means were imputed for all missing continuous data and modes were imputed for all missing categorical data [31]. Data were analysed using SPSS software version 12 (Chicago, IL, USA).

\section{Results}

Characteristics of the study population are presented in Table 1 . Of the 536 medical records examined, $49.4 \%$ (265) of patients prematurely withdrew from recommended services and only $24.8 \%$ (134) attended education classes. Of those who participated in education classes, $88.5 \%$ attended all 3 days of classes and $64.1 \%$ returned for at least one or more of the three group follow-ups.

The global test of all predictors in the multivariable regression model was statistically significant $\left(\chi^{2}=51.31\right.$, d.f. $\left.18, P<0.001\right)$. The $\chi$ statistic of 0.68 [CI $0.63-0.72$ ] indicated that the predictors showed an acceptable ability to distinguish between users and nonusers of ongoing services. The model appeared to fit the data well (Hosmer-Lemeshow goodness-of-fit chi-square of $P=0.928$ ). Patients who were 45 years of age or younger and 65 years of age or older had greater odds of being non-users of ongoing services than those who were middle-aged. Cantonese and Portuguesespeaking patients had lower odds of being non-users compared with English-speaking patients. Those who were unemployed also had lower odds of being non-users compared with those who worked full- or part-time. Only a trend was seen with those who were retired in the multivariate model (see Table 2).

The global test of the full multivariable model for non-use of group education was statistically significant $\left(\chi^{2}=64.98\right.$, d.f. 13 , $P<0.001$ ). The $\chi$ statistic of 0.72 [CI $0.68-0.77$ ] indicated that the predictors showed an acceptable ability to distinguish between users and non-users of group education. The model also appeared to fit the data well (Hosmer-Lemeshow goodness-of-fit chi-square of $P=0.31$ ). Patients who were 65 years of age or older had greater odds of being non-users of group education compared with
Table 1 Characteristics of research subjects $(n=536)$

\begin{tabular}{|c|c|c|}
\hline Characteristic & $\%(n)$ & Mean (SD) \\
\hline Sex & $52.4(281)$ & \\
\hline \multicolumn{3}{|l|}{ Female } \\
\hline Age continuous (years) & & $59.6(12.2)$ \\
\hline \multicolumn{3}{|l|}{ Age categories (years) } \\
\hline$\leq 49$ & $42.2(227)$ & \\
\hline $50-64$ & $20.7(111)$ & \\
\hline$\geq 65$ & $36.9(198)$ & \\
\hline \multicolumn{3}{|l|}{ Primary language spoken } \\
\hline English & $33.2(178)$ & \\
\hline Portuguese & $31.2(167)$ & \\
\hline Cantonese & $16.2(87)$ & \\
\hline Other (Italian, Spanish, Vietnamese) & $19.4(104)$ & \\
\hline \multicolumn{3}{|l|}{ Employment status } \\
\hline Full- or part-time work & $31.3(168)$ & \\
\hline Unemployed & $28.9(155)$ & \\
\hline Retired & $33.6(180)$ & \\
\hline Years living with diabetes (years) & & $3.5(0.4,10)^{*}$ \\
\hline \multicolumn{3}{|l|}{$\begin{array}{l}\text { Recently diagnosed with diabetes } \\
\text { ( } \leq 12 \text { months since diagnosis) }\end{array}$} \\
\hline Yes & $37.5(191)$ & \\
\hline Age of diagnosis (years) & & $52.9(12.1)$ \\
\hline \multicolumn{3}{|l|}{ Type of medical management } \\
\hline Medical nutrition therapy & $22.0(118)$ & \\
\hline Oral agents & $64.9(348)$ & \\
\hline Insulin & $11.2(60)$ & \\
\hline Body mass index & & $30.3(6.31)$ \\
\hline \multicolumn{3}{|l|}{ Referral } \\
\hline Family doctor & $48.1(258)$ & \\
\hline Diabetes specialist/endocrinologist & $27.6(148)$ & \\
\hline Other & $19.6(105)$ & \\
\hline Self & $3.4(18)$ & \\
\hline $\begin{array}{l}\text { Distance from patients' residence to } \\
\text { DEC }(\mathrm{km})\end{array}$ & & $5.5(2.90,10.82)^{*}$ \\
\hline Number of individual follow-up visits & & $2(0,3)^{*}$ \\
\hline
\end{tabular}

Note: Some percentages may not add up to $100 \%$ due to missing data. * Median and interquartile range.

$\mathrm{DEC}$, diabetes education centre.

their middle-aged counterparts. Those who primarily spoke Cantonese, Portuguese or one of the other non-English languages had lower odds of being non-users of group education compared with those who primarily spoke English. Also, patients who were unemployed or retired had lower odds of being non-users of group education compared with those who work full- or part-time (see Table 2).

\section{Discussion}

Although self-management programmes have been instituted to deliver DSME, our findings show that only half of new DEC patients continue to use these services as recommended. Despite these publicly funded services, a mere $25 \%$ of patients attended education classes; a slightly lower proportion than those reported in a population-based survey in the USA [7]. For usual diabetes care in the community, patients are often seen solely by their doctor and given a brief explanation about the disease. Many 
Table 2 Bivariate and multivariable logistic regression: predictive model of attrition from DSME and non-use of education classes

\begin{tabular}{|c|c|c|c|c|}
\hline \multirow[b]{2}{*}{ Characteristic } & \multicolumn{2}{|c|}{$\begin{array}{l}\text { Attrition from DSME }(n=536) \\
\text { multivariable }\end{array}$} & \multicolumn{2}{|c|}{$\begin{array}{l}\text { Non-use of education classes }(n \neq 536) \\
\text { multivariable }\end{array}$} \\
\hline & OR $(95 \% \mathrm{Cl})$ & $P$-value & OR $(95 \% \mathrm{Cl})$ & $P$-value \\
\hline \multicolumn{5}{|l|}{ Sex } \\
\hline Female & 1.00 (referent) & - & 1.00 (referent) & - \\
\hline Male & $0.95(0.65-1.38)$ & 0.779 & $1.06(0.68-1.65)$ & 0.813 \\
\hline Age (years) & & 0.025 & & 0.025 \\
\hline$\leq 49$ & $1.71(1.01-2.86)$ & 0.049 & $1.62(0.83-3.16)$ & 0.154 \\
\hline $50-64$ & 1.00 (referent) & - & 1.00 (referent) & - \\
\hline$\geq 65$ & $1.74(1.06-2.69)$ & 0.027 & $2.60(1.56-4.35)$ & 0.000 \\
\hline Primary language spoken & & 0.017 & & 0.000 \\
\hline English & 1.00 (referent) & - & 1.00 (referent) & - \\
\hline Cantonese & $0.42(0.23-0.77)$ & 0.005 & $0.21(0.10-0.41)$ & 0.000 \\
\hline Portuguese & $0.53(0.32-0.90$ & 0.018 & $0.48(0.26-0.91)$ & 0.023 \\
\hline Other (Italian, Spanish, Vietnamese) & $0.74(0.43-1.27)$ & 0.274 & $0.42(0.21-0.81)$ & 0.010 \\
\hline Referral & & 0.465 & - & \\
\hline Family doctor & 1.00 (referent) & - & - & \\
\hline Endocrinologist/diabetes specialist & $1.33(0.85-2.09)$ & 0.216 & - & \\
\hline Other (e.g. self-referrał) & $1.12(0.70-1.80)$ & 0.632 & - & \\
\hline Employment & & 0.002 & & 0.000 \\
\hline Full or part-time work & 1.00 (referent) & - & 1.00 (referent) & - \\
\hline Unemployed & $0.42(0.26-0.68)$ & 0.001 & $0.37(0.16-0.84)$ & 0.000 \\
\hline Retired & $0.61(0.35-1.05)$ & 0.077 & $0.53(0.26-1.10)$ & 0.000 \\
\hline Symptoms & $0.90(0.79-1.01)$ & 0.077 & $0.88(0.77-1.02)$ & 0.083 \\
\hline Body mass index & $1.05(0.90-1.22)$ & 0.535 & & 0.060 \\
\hline Type of medical management & & 0.346 & & 0.018 \\
\hline Medical nutrition therapy & $0.79(0.38-1.61)$ & 0.512 & $0.37(0.16-0.08)$ & 0.088 \\
\hline Oral agents & $0.67(0.37-1.21)$ & 0.179 & $0.53(0.26-1.10)$ & - \\
\hline Insulin & 1.00 (referent) & - & 1.00 (referent) & \\
\hline Blood glucose self-monitoring & & & - & - \\
\hline Yes & 1.00 (referent) & - & - & - \\
\hline No & $0.91(0.62-1.34)$ & 0.640 & - & - \\
\hline Smoking & & & - & - \\
\hline Yes & 1.00 (referent) & - & 1.00 (referent) & \\
\hline No & $1.19(0.70-2.03)$ & 0.523 & $1.202(0.63-2.30)$ & 0.576 \\
\hline Exercise & & & & - \\
\hline Yes & 1.00 (referent) & - & - & - \\
\hline No & $1.38(0.94-2.03)$ & 0.106 & - & \\
\hline Distance travelled to centre (10-km units) & $1.04(0.95-1.13)$ & 0.393 & $1.02(0.98-1.13)$ & 0.747 \\
\hline
\end{tabular}

-, the predictor variable was not tested for this outcome (non-use of education classes): DSME, diabetes self-management training.

patients do not receive in-depth lifestyle education and training due to doctors' time constraints and heavy caseloads [32]. Thus, a high attrition rate from DSME raises concerns about a patient's source of information, support and skills to manage their diabetes and maintain optimal health.

For many years, the burden of diabetes has tended to be highest among minority groups [33]. These groups are reported to have poorer glycemic control, as well as limited access to diabetes selfmanagement resources and support [8,33-35]. Studies have shown that non-English-speaking patients are less likely to participate in DSME programmes [35] and less likely to adopt self-management behaviours if the delivery of information is not culturally relevant and language specific [36]. To address these issues, the participating DEC has developed a series of six culturally competent DSME programmes, which provided the opportunity to analyse the use of these culturally competent services across language groups. In our study, those who primarily spoke a non-English language were more likely to use services as recommended, including education classes, than English-speaking patients. In addition to other studies, our findings demonstrate that culturally relevant and language specific education services are effective in retaining nonEnglish-speaking patients $[22,37]$. The only other study assessing the impact of primary language on DSME attrition found no link between primary language and use of DSME services [12]. However, education services culturally tailored to non-English speakers were not available within this health management organization.

Services that address cultural attitudes, values, practices, and language barriers are also known to increase a patient's communication, trust and satisfaction with care providers [38,39], which in turn may increase patient adherence to recommended educational 
interventions and treatments. Although English-speaking patients were less likely to return for follow-up services, it is possible that they are using other informal or self-directed learning resources such as books or the Internet, which may not be available or accessible to non-English-speaking patients. Nonetheless, further research needs to confirm this speculation.

Our results also suggest that those who were unemployed were more likely to use follow-up services and group education. It is likely that DSME services offered during standard work hours are less accessible to individuals who work during the day. For instance, people may not receive financial compensation for time taken from work or they may hesitate to request time off from employers. Therefore, improvement in accessibility and uptake of services requires change to how DSME services are delivered. Some suggestions include offering educational services during alternative hours, or as a component of health care in the workplace and at common meeting places, such as community centres or places of worship. Moreover, DSME programmes should offer choice through a range of convenient education options via Internet [40], mail [41] or telephone [42-44], which may also attract and retain more patients [45]. Further research is needed to evaluate a combination of alternative methods of delivering DSME and its affect on retention.

Evidence of age as a predictor of programme attrition or missed diabetes care appointments has been inconsistent in the diabetes literature with some studies reporting an association $[17,21,22,28,46]$, while others not finding an association $[10,12,15,25,26]$. We found that patients younger than 45 and aged 65 years or older were more likely to drop out from recommended services. Patients 65 years of age or older were also less likely to attend group education. Similar findings were reported for never using DSME, where persons with type 2 diabetes aged 1834 years and aged 75 years or older were more likely not to participate in DSME in the 2001/02 Behavioural Risk Factor Surveillance System Survey [8]. Older age has been reported as a barrier to accessing diabetes-related health resources [47]. As older patients may be less mobile or active [48], have smaller social networks [49] and may prefer to take a more passive role in their health care treatment [50], they may be incapable or unmotivated to use health resources. Some of the implications for the planning and implementation of DSME for senior patients include the need to develop alternative services such as, in-home or telephone care that would be more feasible and convenient for older patients who find it physically and financially challenging to travel to the DEC. Collaboration or integration with senior wellness and DSME programmes may be an effective means of reaching out to seniors who would not regularly use DSME services.

Overall, our findings suggest those who are older and work fullor part-time have barriers or inequitable access to DSME services. These factors are modifiable and provide encouragement for the restructuring of how DSME services are delivered, which can positively affect programme retention.

This study had the strength of a relatively large sample size and had the opportunity to analyse attrition rates in a centre that provides culturally competent services in six different language groups. With the increase in globalization and international migration, our study results may be relevant to many existing DECs internationally. Given that this was a retrospective study, our analyses were limited to what data were available and complete in patient medical records. Furthermore, use of health care services is a complex, multidimensional phenomenon, and other sociodemographic, psychosocial, clinical and contextual factors were not available for analysis. We were also unable to identify patients who may have moved or died during the study period. Without having this information, our attrition rate may be inflated. However, this rate may also be under reported given we excluded $50 \%$ of English-speaking patients from our study. This study was conducted within one DEC; therefore, our results may not be generalizable to all DSME interventions.

\section{Conclusions}

This article addresses an important public health issue in diabetes education practice and care, that of retaining patients in DSME. The high attrition rate from these programmes indicates that retention needs to become a focus of programme policy, planning and evaluation to improve their effectiveness. We need to identify factors that can explain low levels of participation and intervene on identified barriers to increase uptake of DSME programmes. Enabling patients by providing DSME that is tailored to the cultural and linguistic characteristics of the community, and accessible and convenient for older and working patients appear to be necessary to increase retention in and accessibility to these services.

\section{Acknowledgements}

The authors would like to thank the Canadian Institute of Health Research (CIHR) for the Canadian Graduate Scholarship doctoral award to E. Gucciardi and for a CIHR postdoctoral award to S.L. Grace, and Dr Gillian Booth and Dr George Tomlinson for their constructive feedback on the manuscript.

\section{References}

1. The Diabetes Control and Complications Trial Research Group (1993) The effect of intensive treatment of diabetes on the development and progression of long-term complications in insulin-dependent diabetes mellitus. The Diabetes Control and Complications Trial Research Group. New England Journal of Medicine, 329 (14), 977-986.

2. UKPDS (1998) Intensive blood-glucose control with sulphonylureas or insulin compared with conventional treatment and risk of complications in patients with type 2 diabetes (UKPDS 33). UK Prospective Diabetes Study (UKPDS) Group. Lancet, 352 (9131), 837-853.

3. Mensing, C., Boucher, J., Cypress, M., et al. (2004) National Standards for Diabetes Self-management Education. Diabetes Care, 27 (90001), 143S.

4. Canadian Diabetes Association Clinical Practice Guidelines Expert Committee (2003) Canadian Diabetes Association 2003 Clinical Practice Guidelines for the Prevention and Management of Diabetes in Canada. Canadian Journal of Diabetes, 27 (Suppl. 2), S14-S15.

5. Norris, S. L., Engelgau, M. M. \& Narayan, K. M. (2001) Effectiveness of self-management training in type 2 diabetes: a systematic review of randomized controlled trials. Diabetes Care, 24 (3), 561-587.

6. Renders, C. M., Valk, G. D., Griffin, S., et al. (2001) Interventions to improve the management of diabetes mellitus in primary care, outpatient and community settings. Cochrane Database Systematic Review, Issue 1, CD001481. 
7. Coonrod, B. A., Betschart, J. \& Harris, M. I. (1994) Frequency and determinants of diabetes patient education among adults in the U.S. population. Diabetes Care, 17 (8), 852-858.

8. Strine, T. W., Okoro, C. A., Chapman, D. P., et al. (2005) The impact of formal diabetes education on the preventive health practices and behaviors of persons with type 2 diabetes. Preventive Medicine, 41 (1), 79-84.

9. Griffin, J. A., Gilliland, S. S., Perez, G., Upson, D. \& Carter, J. S. (2000) Challenges to participating in a lifestyle intervention program: the Native American Diabetes Project. Diabetes Educator, 26 (4), 681-689.

10. Graber, A. L., Davidson, P., Brown, A. W., McRae, J. R. \& Woolridge, K. (1992) Dropout and relapse during diabetes care. Diabetes Care, 15 (11), 1477-1483.

11. Whitehouse, F. W., Whitehouse, I. J., Smith, J. \& Hohl, R. D. (1979) Teaching the person with diabetes: experience with a follow-up session. Diabetes Care, 2 (1), 35-38.

12. Benoit, S. R., Ji, M., Fleming, R. \& Philis-Tsimikas, A. (2004) Predictors of dropouts from a San Diego diabetes program: a case control study. Preventing Chronic Diseases, 1 (4), A10.

13. Archibald, L. \& Gill, G. (1992) Diabetic clinic defaulters-who are they and why do they default? Practical Diabetes, 9, 13-14.

14. Kellett, J. (1988) Diabetes clinic attendance and metabolic control. A pilot pan clinic study. Annales de médecine interne (Paris), 139 (2), 95-97.

15. Kawahara, R., Amemiya, T., Yoshino, M., et al. (1994) Dropout of young non-insulin-dependent diabetics from diabetic care. Diabetes Research and Clinical Practice, 24 (3), 181-185.

16. Hammersley, M. S., Holland, M. R., Walford, S. \& Thorn, P. A. (1985) What happens to defaulters from a diabetic clinic? British Medical Journal (Clin. Res. Ed.), 291 (6505), 1330-1332.

17. Rhee, M. K., Slocum, W., Ziemer, D. C., et al. (2005) Patient adherence improves glycemic control. Diabetes Educator, 31 (2), 240-250.

18. Marcus, B. H., Nigg, C. R., Riebe, D. \& Forsyth, L. H. (2000) Interactive communication strategies: implications for populationbased physical-activity promotion. American Journal of Preventative Medicine, 19 (2), 121-126.

19. Nigg, C. R., Allegrante, J. P. \& Ory, M. (2002) Theory-comparison and multiple-behavior research: common themes advancing health behavior research. Health Education Research, 17 (5), 670-679.

20. Scobie, I. N., Rafferty, A. B., Franks, P. C. \& Sonksen, P. H. (1983) Why patients were lost from follow-up at an urban diabetic clinic. British Medical Journal (Clin. Res. Ed.), 286 (6360), 189-190.

21. Irvine, A. A. \& Mitchell, C. M. (1992) Impact of community-based diabetes education on program attenders and nonattenders. Diabetes Educator, 18 (1), 29-33.

22. Corkery, E., Palmer, C., Foley, M. E., et al. (1997) Effect of a bicultural community health worker on completion of diabetes education in a Hispanic population. Diabetes Care, 20 (3), 254-257.

23. Simmons, D., Weblemoe, T., Voyle, J., et al. (1998) Personal barriers to diabetes care: lessons from a multi-ethnic community in New Zealand. Diabetes Medicine, 15 (11), 958-964.

24. Lloyd, J., Sherriff, R., Fisher, M. \& Burns-Cox, C. (1990) Nonattendance at the diabetic clinic. Practice Diabetes, 7, 228-229.

25. Jacobson, A. M., Adler, A. G., Derby, L., Anderson, B. J. \& Wolfsdorf, J. I. (1991) Clinic attendance and glycemic control. Study of contrasting Groups of patients with IDDM. Diabetes Care, 14 (7), 599-601.

26. Funnell, M. M., Arnold, M. S., Fogler, J., Merritt, J. H. \& Anderson, L. A. (1997) Participation in a diabetes education and care program: experiences from the diabetes care for older adults project. Diabetes Educator, 23 (2), 163-167.

27. Spikmans, J. M., Brug, J., Doven, M. B., et al. (2003) Why do diabetic patients not attend appointments with their dietitian? Journal of Human Nutrition and Dietetics, 16 (3), 151-158.
28. Karter, A. J., Parker, M. M., Moffet, H. H., et al. (2004) Missed appointments and poor glycemic control: an opportunity to identify high-risk diabetic patients. Medical Care, 42 (2), 110-115.

29. Steyerberg, E. W., Eijkemans, M. J., Harrell, F. E. Jr \& Habbema, J. D. (2001) Prognostic modeling with logistic regression analysis: in search of a sensible strategy in small data sets. Medical Decision Making, 21 (1), 45-56.

30. Peduzzi, P., Concato, J., Kemper, E., Holford, T. R. \& Feinstein, A. R. (1996) A simulation study of the number of events per variable in logistic regression analysis. Journal of Clinical Epidemiology, 49 (12), 1373-1379.

31. Fairclough, D. L. (2002) Design and Analysis of Quality of Life Studies in Clinical Trials. New York: Chapman \& Hall.

32. Hiss, R. G., Frey, M. S. \& Davis, W. K. (1986) Diabetes patient education in the office setting. Diabetes Educator, 12 (3), 281-285.

33. Carter, J. S., Pugh, J. A. \& Monterrosa, A. (1996) Non-insulindependent diabetes mellitus in minorities in the United States. Annals of International Medicine, 125 (3), 221-232.

34. Koro, C. E., Bowlin, S. J., Bourgeois, N. \& Fedder, D. O. (2004) Glycemic control from 1988 to 2000 among U.S. adults diagnosed with type 2 diabetes: a preliminary report. Diabetes Care, 27 (1), 1720.

35. Bruce, D. G., Davis, W. A., Cull, C. A. \& Davis, T. M. (2003) Diabetes education and knowledge in patients with type 2 diabetes from the community: the Fremantle Diabetes Study. Journal of Diabetes Complications, 17 (2), 82-89.

36. Karter, A. J., Ferrara, A., Darbinian, J. A., Ackerson, L. M. \& Selby, J. V. (2000) Self-monitoring of blood glucose: language and financial barriers in a managed care population with diabetes. Diabetes Care, 23 (4), 477-483.

37. Anderson, R. M., Herman, W. H., Davis, J. M., et al. (1991) Barriers to improving diabetes care for blacks. Diabetes Care, 14 (7), 605-609.

38. Collins, K. S., Hughes, D. L., Doty, M. M., et al. (2002) Diverse Communities, Common Concerns: Assessing Health Care Quality for Minority Americans. New York: The Commonwealth Fund.

39. Cooper, L. A., Roter, D. L., Johnson, R. L., et al. (2003) Patientcentered communication, ratings of care, and concordance of patient and physician race. Annals of International Medicine, 139 (11), 907915.

40. McKay, H. G., Feil, E. G., Glasgow, R. E. \& Brown, J. E. (1998) Feasibility and use of an Internet support service for diabetes selfmanagement. Diabetes Educator, 24 (2), 174-179.

41. Anderson, R. M., Fitzgerald, J. T., Funnell, M. M., et al. (1994) Evaluation of an activated patient diabetes education newsletter. Diabetes Educator, 20 (1), 29-34.

42. Piette, J. D., Weinberger, M., McPhee, S. J., et al. (2000) Do automated calls with nurse follow-up improve self-care and glycemic control among vulnerable patients with diabetes? American Journal of Medicine, 108, 20-27.

43. Kim, H. S. \& Oh, J. A. (2003) Adherence to diabetes control recommendations: impact of nurse telephone calls. Journal of Advanced Nursing, 44 (3), 256-261.

44. Weinberger, M., Kirkman, M. S., Samsa, G. P., et al. (1995) A nursecoordinated intervention for primary care patients with noninsulin-dependent diabetes mellitus: impact on glycemic control and health-related quality of life. Journal of General Internal Medicine, $10(2), 59-66$.

45. McLeod, B. (2000) Research in diabetes education: where have we been and where do we need to go? Canadian Journal of Diabetes Care, 22 (2), 20-28.

46. Simmons, D. \& Fleming, C. (2000) Prevalence and characteristics of diabetic patients with no ongoing care in South Auckland. Diabetes Care, 23 (12), 1791-1793. 
47. Gucciardi, E., Smith, T. \& DeMelo, M. (2006) Use of diabetes resources in adults attending a self-management education program. Patient Education and Counselling, 64 (1-3), 322-330.

48. Schutzer, K. A. \& Graves, B. S. (2004) Barriers and motivations to exercise in older adults. Preventative Medicine, 39 (5), 1056-1061.

49. Keller, B. K., Magnuson, T. M., Cernin, P. A., Stoner, J. A. \& Potter, J. F. (2003) The significance of social network in a geriatric assess- ment population. Aging Clinical and Experimental Research, 15 (6), 512-517.

50. Charles, C., Redko, C., Whelan, T., Gafni, A. \& Reyno, L. (1998) Doing nothing is no choice: lay constructions of treatment decisionmaking among women with early-stage breast cancer. Sociology of Health and Illness, 20, 71-95. 